\title{
The influence evaluation of municipal government Website in Guangxi Zhuang Autonomous Region based on link analysis
}

\author{
Yanan Song ${ }^{1 s t, a}$, Erli Liu ${ }^{2 r d, b}$ \\ ${ }^{1}$ School of Management Guangxi University for Nationalities Nanning, China \\ ${ }^{2}$ School of Management Guangxi University for Nationalities Nanning, China
}

\begin{abstract}
This study uses Google chrome as a tool, combined with advanced search styles to retrieve related website links, and uses link analysis methods to comprehensively analyze the influence of 14 prefecture-level municipal government portals in Guangxi Zhuang Autonomous Region. At the same time, the analysis results are sorted by using the gray correlation analysis method through EXCEL. The evaluation results show that the relevance of the government portals of prefecture-level cities in Guangxi is generally between 0.7 and 0.9 , and improvement strategies are proposed on this basis.
\end{abstract}

\section{INTRODUCTION}

With the continuous development of big data and cloud computing technology, people's requirements for government governance capabilities and governance levels continue to increase. Today, as the pace of "digital government" is constantly advancing, government portals are not only an important channel for the public to understand government affairs information and obtain related services but also an important window for presenting regional cultural characteristics and promoting the image of the government. In 2017, the Guangxi Zhuang Autonomous Region government issued a series of relevant documents to begin unified deployment and management of government websites, establish a progressive supervision model and corresponding systems to promote the continuous development of informatization. The results of the performance evaluation of the Chinese government website in 2019 showed that the Guangxi Zhuang Autonomous Region was at a good level in the evaluation of digital government service capabilities, and the website performance evaluation results ranked fourth among the provincial portals and obtained excellent achievements in the construction of government websites.

At present, scholars from various countries use various methods to study the construction of government websites and have achieved different research results. Jyoti; George and Vishanth(2004) think that there wide variations in the spectrum of information and services provided by Global e-Government Sites[1]. Naci and Marijn(2014) believe that public values should be included in the evaluation of websites and other public efforts[2]. The study of Gregory (2016) suggested that disclosure of information on government websites can improve the relationship between citizens and the government to a certain extent [3]. In China, Yongzhong Sha and Xia Ouyang (2004) used link analysis methods and web impact factor measurement methods to evaluate the influence of provincial government websites [4]. Jinlong Yang; Qianli Liu and Xia $\mathrm{Wu}$ (2019) used the website link analysis method to study the shortcomings of provincial government websites in the construction of e-government and gave suggestions [5]. Through the literature review, it is not difficult to find that the network link analysis method can better reflect the influence of the website. Therefore, analyzing and researching the influence of the Guangxi municipal government website to find out the influence factors and promotion strategies of the website influence can promote the development and progress of Guangxi e-government.

\section{Methodology}

\subsection{Determination of research objects}

According to the data released by the Big Data Development Bureau of Guangxi Zhuang Autonomous Region, as of the second quarter of 2020, there are 557 government websites in operation in the region, including 1 autonomous region people's government portal website and 111 county-level government portal websites. This study selected 14 well-functioning people's government portal websites as research objects

\subsection{Selection of research indicators}

As an important window for the disclosure of government information and an important bridge for providing public services to the people, government portals have distinctive service and social features. It not only highlights the service function of the government website, but also 
highlights its cultural propaganda function. After comprehensively reviewing relevant studies and analyzing the specific operating conditions of relevant websites select Webpages; Total link; Internal link; External link; web impact factor (WIF total); internal web impact factor (WIF in); external web impact factor (WIF ex); Friendship link to analyze the influence of the website. All in all, the number of web pages refers to the total number of web pages included in the chrome browser, which reflects the richness of various information resources in the website. The total number of links of a website consists of Internal links: hyperlinks on some other websites that are directing visitors to a website and external links: hyperlinks allowed the site visitors to access the other websites [6]. The web impact factor is the ratio of the number of web pages linked to a specific website or area on the network at a certain time to the number of web pages contained in the website or area itself, web impact factor is divided into external web impact factor and internal web impact factor [7]. The number of friendly links refers to the number of links to other websites on your own website. Friendship links must be able to find the URL and website name in the page code, and the website name can be displayed when browsing the web. Friendship links must be able to find the URL and website name in the page code.

\subsection{Choice of research tools}

In the research of network link extraction and analysis, the choice of a search engine, and the use of matching search styles will have a greater impact on the search results. Taking into account the performance and algorithms of search engines and the different ways of ranking web pages, this study uses chrome developed by Google as the search engine to ensure the accuracy of the search results. Google supports link domain and host search commands to obtain the number of total links and internal links to the website [8]. At the same time, check the number of friendly links on the website through the home of the largest comprehensive website in China. The index retrieval formula is shown in Table I (take the portal website of Nanning Municipal People's Government as an example):

Table I Statistical Index Search Formula

\begin{tabular}{|l|l|}
\hline \multicolumn{2}{|c|}{ Index summary table } \\
\hline \multicolumn{1}{|c|}{ Index } & \multicolumn{1}{c|}{ Formula } \\
\hline Web pages & site: www.nanning.gov.cn \\
\hline Total links & "www.nanning.gov.cn" \\
\hline Internal links & $\begin{array}{l}\text { site:www.nanning.gov.cn } \\
\text { +"www.nanning.gov.cn" }\end{array}$ \\
\hline External links & Total link -Web page \\
\hline WIF total & Total link/ Web page \\
\hline WIF in & Internal link/ Web page \\
\hline WIF ex & external link / Web page \\
\hline Friendship links & www.chinaz.com \\
\hline
\end{tabular}

\section{RESEARCH DATA PROCESSING}

By using Google's Chrome browser combined with related search formulas to search, the author obtained the specific data of 8 link analysis indicators of 14 Guangxi prefecture-level city portal websites (see Table II and Table III).

From previous studies, the larger the number of the above eight indicators, the more complete the website is in related aspects, the stronger the internal structure and external radiation capabilities of the website, and the stronger the influence of the website [9]. Observing TableII Table III found that the influence of 14 websites cannot be judged intuitively. Limited by the size of the sample and the number of collections, regression analysis cannot be used to analyze the relationship between various indicators. Therefore, this study uses the grey relational analysis method to analyze the collected samples.

TABLE II LINKS TO THE GUANGXI GOVERNMENT WEBSITE

\begin{tabular}{|l|l|l|l|l|}
\hline \multicolumn{5}{|c|}{ Link Analysis Index Table of Guangxi Government } \\
Website \\
\hline \multicolumn{1}{|c|}{ Area } & Webpages & $\begin{array}{c}\text { total } \\
\text { links }\end{array}$ & $\begin{array}{c}\text { Internal } \\
\text { links }\end{array}$ & $\begin{array}{c}\text { external } \\
\text { links }\end{array}$ \\
\hline Nanning & 38900 & 45200 & 38700 & 6500 \\
\hline Liuzhou & 21100 & 27900 & 21000 & 6900 \\
\hline Guilin & 4020 & 5410 & 3890 & 1520 \\
\hline Wuzhou & 1370 & 1660 & 621 & 1039 \\
\hline Beihai & 49000 & 49200 & 42500 & 6700 \\
\hline $\begin{array}{l}\text { Fang } \\
\text { chenggang }\end{array}$ & 31600 & 32600 & 31620 & 980 \\
\hline Qinzhou & 5140 & 6140 & 5070 & 1070 \\
\hline Guigang & 2740 & 4570 & 2810 & 1760 \\
\hline Yulin & 1780 & 4190 & 1610 & 2580 \\
\hline Baise & 2200 & 4480 & 2300 & 2180 \\
\hline Hezhou & 2140 & 2810 & 2120 & 690 \\
\hline Hechi & 1990 & 3230 & 1970 & 1260 \\
\hline Laibin & 3010 & 3590 & 3020 & 570 \\
\hline Chongzuo & 1650 & 2910 & 1620 & 1290 \\
\hline
\end{tabular}

TABLE III LINKS TO THE GUANGXI GOVERNMENT WEBSITE

\begin{tabular}{|l|l|l|l|l|}
\hline \multicolumn{5}{|c|}{ Link Analysis Index Table of Guangxi Government } \\
Wrea & $\begin{array}{c}\text { WIF } \\
\text { total }\end{array}$ & WIF in & WIF ex & $\begin{array}{c}\text { Friend } \\
\text { link }\end{array}$ \\
\hline Nanning & 1.162 & 0.9949 & 0.1671 & 50 \\
\hline Liuzhou & 1.3223 & 0.9953 & 0.327 & 68 \\
\hline Guilin & 1.3458 & 0.9677 & 0.3781 & 83 \\
\hline Wuzhou & 1.2117 & 0.4533 & 0.7584 & 18 \\
\hline Beihai & 1.0041 & 0.8673 & 0.1367 & 32 \\
\hline Fangchenggang & 1.0316 & 1.0006 & 0.031 & 24 \\
\hline Qinzhou & 1.1946 & 0.9864 & 0.2082 & 19 \\
\hline Guigang & 1.6679 & 1.0255 & 0.6423 & 26 \\
\hline Yulin & 2.3539 & 0.9045 & 1.4494 & 30 \\
\hline Baise & 2.0364 & 1.0455 & 0.9909 & 26 \\
\hline Hezhou & 1.3131 & 0.9907 & 0.3224 & 12 \\
\hline Hechi & 1.6231 & 0.9899 & 0.6332 & 38 \\
\hline Laibin & 1.1927 & 1.0033 & 0.1894 & 32 \\
\hline
\end{tabular}




\begin{tabular}{|l|l|l|l|l|}
\hline Chongzuo & 1.7636 & 0.9818 & 0.7818 & 35 \\
\hline
\end{tabular}

The grey relational analysis method is proposed by the famous scholar Julong Deng which is mainly used to measure the degree of relation between the elements of the system. It is a kind of grey system analysis method [10]. The main steps of the gray relational analysis method are as follows: First, select each value of the reference item as the reference value, and record it as $\mathrm{X}_{0}$. Then respectively calculate the absolute difference between each index data $\left(\mathrm{X}_{1}, \mathrm{X}_{2}, \ldots, \mathrm{X}_{\mathrm{n}}\right)$ and its reference value, and select a maximum value and a minimum value from the difference of each index, denoted as $\max \mid \mathrm{X}_{0}(\mathrm{k})$ $\mathrm{X}_{\mathrm{i}}(\mathrm{k}) \mid$ and $\min \left|\mathrm{X}_{0}(\mathrm{k})-\mathrm{X}_{\mathrm{i}}(\mathrm{k})\right|$. Finally, select a maximum value and a minimum value from the values of $\max \mid \mathrm{X}_{0}(\mathrm{k})$ $\mathrm{X}_{\mathrm{i}}(\mathrm{k}) \mid$ and $\min \left|\mathrm{X}_{0}(\mathrm{k})-\mathrm{X}_{\mathrm{i}}(\mathrm{k})\right|$, which are denoted as $\operatorname{maxmax}\left|\mathrm{X}_{0}(\mathrm{k})-\mathrm{X}_{\mathrm{i}}(\mathrm{k})\right|$ and $\operatorname{minmin}\left|\mathrm{X}_{0}(\mathrm{k})-\mathrm{X}_{\mathrm{i}}(\mathrm{k})\right|$. After calculating the correlation value, referring to the calculation of the correlation coefficient, respectively calculate the correlation coefficient of each comparison sequence and the corresponding element of the reference sequence, as shown in formula (1)

$$
\varepsilon_{\mathrm{i}}(k)=\frac{\min \min \left|X_{0}(K)-X_{i}(K)\right|+\beta \max \max \left|X_{0}(K)-X_{i}(K)\right|}{\left|X_{0}(K)-X_{i}(K)\right|+\beta \max \max \left|X 0(K)-X_{i}(K)\right|}
$$

In formula (1), $\beta$ is the resolution coefficient, which is taken in $(0,1)$. If $\beta$ is smaller, the difference between correlation coefficients is greater, and the discrimination ability is stronger. Usually $\beta$ is $0.5, X_{0}(\mathrm{k})$ is the maximum In the column of merit data, $\varepsilon_{i}(k)$ is the calculated correlation coefficient.

The correlation degree value between the various platform data, that is, the correlation degree $\mathrm{S}(\mathrm{k})$ is calculated according to formula (2), and is the average value of the correlation coefficient of each indicator.

$$
S(k)=\frac{1}{n} * \sum_{k=1}^{n} \varepsilon_{i}(k)
$$

Based on the 8 items of data of 14 prefecture-level city government portal websites in Guangxi and, the grey correlation analysis is carried out to study the correlation between the 14 Guangxi prefecture-level city government websites (correlation degree), and then the correlation coefficient value (resolution coefficient $\beta$ Take 0.5), and finally calculate the correlation value for evaluation and judgment by Excel. Table IV shows the relevance value and ranking of Guangxi prefecture-level city government portal websites calculated according to the above steps.

TABLe IV ReleVANCE RANKING

\begin{tabular}{|c|l|l|}
\hline \multicolumn{3}{|c|}{ Relevance results } \\
\hline Evaluation item & Correlation & Rank \\
\hline Nanning & 0.935 & 2 \\
\hline Liuzhou & 0.874 & 7 \\
\hline Guilin & 0.851 & 8 \\
\hline Wuzhou & 0.788 & 10 \\
\hline Beihai & 0.993 & 1 \\
\hline Fangchenggang & 0.921 & 5 \\
\hline Qinzhou & 0.927 & 4 \\
\hline Guigang & 0.774 & 11 \\
\hline Yulin & 0.716 & 14 \\
\hline Baise & 0.731 & 13 \\
\hline Hezhou & 0.876 & 6 \\
\hline Hechi & 0.791 & 9 \\
\hline
\end{tabular}

\begin{tabular}{|c|l|l|}
\hline Laibin & 0.927 & 3 \\
\hline Chongzuo & 0.768 & 12 \\
\hline
\end{tabular}

\section{Evaluation RESUlt anAlysis}

\subsection{Some websites are highly relevant and influential}

In recent years, the Guangxi Zhuang Autonomous Region government has continuously strengthened its efforts to construct government websites at all levels in the region. The construction of government websites in various cities in Guangxi has made great progress, and the website content and website functions have been improved day by day. Judging from the relevance ranking results, the relevance values of 14 government portal websites in Guangxi all exceed 0.7. Among them, the relevance of Beihai, Nanning, Laibin, Qinzhou, and Fangchenggang are above 0.9, and the relevance of Hezhou, Liuzhou, Guilin, above 0.8. Taking the average of the relevance of 14 government portals of 0.848 as the reference standard, it can be seen that the relevance of 8 prefecture-level city government portals is higher than the average, accounting for $57 \%$ of the total. Analyzing the specific indicators of each website combined with the relevance value, it can be seen that each website has less construction efforts.

\subsection{There are construction gaps in different websites}

The relevance of Hezhou, Liuzhou, Guilin and other websites is above 0.8. Although the overall degree of relevance is relatively high, there is still a large gap between the relevance of various websites. The difference of relevance between Beihai City and Yulin City has reached 0.27 . This also reflects that the development of each website is different, and there are also gaps in the intensity of construction and maintenance. In addition to the degree of relevance, the number of web pages is also an important basis for reflecting the status of website construction. From the table, we can see that among the 14 websites, the number of pages on the four portal websites of Beihai, Nanning, Liuzhou, and Fangchenggang is relatively high, exceeding 10,000 . However, the remaining 10 websites have relatively few pages. The number of webpages is the total number of webpages on this website that can be retrieved by search engines. Users can only browse and interact normally after checking out the search engine and entering the relevant interface. Therefore, the number of web pages is closely related to the richness of website content and website user satisfaction. After comparing the top-ranked Nanning Municipal Government Portal and Yulin Municipal Government's portal website, it is found that there are 8 first-level categories on the homepage of Nanning Municipal Government's portal website, while Yulin Municipal Government's portal website has only 7 first-level categories. At the same time, the total number of pages detected by government portal information websites in prefecture-level cities such as Wuzhou, Hechi, 
and Chongzuo is relatively small, and the information resources presented on the websites are relatively poor, which is not conducive to the development of government information disclosure.

\subsection{External influence of the website are relatively low}

The network impact factor is one of the important indicators to measure the network influence of a website. The value of this indicator is the ratio of the total number of web pages to the number of network links. This calculation method causes the network impact factor to be greatly affected by the number of web pages. Therefore, the value can only be combined with other indicators that carry out a specific analysis. Because of the different link types measured, the network impact factor is divided into external impact factors and internal network impact factors. After analyzing the internal network influence factors and external network influence factors and related indicators of 14 prefecture-level government portal websites in Guangxi, it is found that most websites have more internal links than external links, which shows that the investment in the construction of structure and content is relatively large, while the investment in the exchange and cooperation between websites and the improvement of influence is relatively small. In addition, the internal network impact factor of each website is higher than the external impact factor. Nanning, Liuzhou, Fangchenggang, Guigang, and other websites with relatively high performance evaluation have relatively low external network influence factors. At the same time, the proportion of external influence factors in the network influence factors is also relatively low. Beihai, Nanning, and Fangchenggang have not reached $15 \%$, and only Liuzhou has reached $20 \%$. All in all, the external influence of the government portal of Guangxi Zhuang Autonomous Region is generally low.

\section{SUggestions}

\subsection{Enrich website content and improve the website structure}

According to the analysis of the number of web pages, the total number of web pages in most of the municipal government portal websites in Guangxi is relatively small. Therefore, improving the internal functional structure of the website and enriching the content of the website can effectively increase the influence of the government portal website. When each website discloses government information, the content can be classified and aggregated according to the actual situation, and the related links of the first-level category and the second-level category on the portal website can be reasonably classified, and the internal links under the same category The content is connected in an orderly manner to form a content aggregation of related categories. This kind of content aggregation enables web crawlers to better understand the structure of the website, and it also helps users find the required information quickly and conveniently.

\subsection{Introduce website optimization technology to enrich link forms}

While rationally deploying content, optimizing the link form is also one of the important ways to improve the website structure and enhance user experience. The number of internal links and the ease of optimization will affect the user's sense of use when browsing the website and experiencing various functions to a certain extent. The common forms of internal links are HTML format, anchor text format, and plain text format. The anchor text format can help Chrome better understand the content of the page. In the process of website operation, the link from the secondary category to the specific content can mostly adopt the anchor text format. This can increase the stability and jump speed of internal links to improve the experience and satisfaction of website users. When operating a website, Search Engine Optimization (SEO) technology can be introduced to improve the website's ranking in search engines, so as to better serve the people.

\subsection{Expand exchanges and actively interact with external parties}

After analyzing the 14 Guangxi prefecture-level city government portal websites, it can be seen that the number of friendly links on each website is generally small. The three government websites of Nanning, Guilin, and Liuzhou have a large number of friendly links, but the number of outbound links is small. After opening the homepages of the three government portals, we found that among the three websites, most of the links of friendship links to subordinate institutions or county-level government websites, and only the links from the Nanning government portal to the official website of the ASEAN Expo. Therefore, 14 portal websites can introduce links from partner agencies' websites on the homepage, and require the other party to display their own links on the homepage. In this way, the number of friendship links will be increased and the quality of external links will be improved.

\section{CONCLUSION}

The purpose of this research is to evaluate the influence of various prefecture-level municipal government portal websites in Guangxi Zhuang Autonomous Region through link analysis and to promote the development of Guangxi e-government on this basis. The study found that the gray correlation coefficient value of each prefecture-level city government portal website is $0.7-0.9$, and the comprehensive construction situation is good. However, there is still a big gap in the internal construction of various websites, and the interaction between websites and websites needs to be strengthened. Therefore, measures have been proposed to strengthen the construction of website content, optimize the internal structure of the website, and enhance communication 
between websites, hoping to promote the construction of various prefecture-level city government portal websites.

\section{REFERENCES}

1. Jyoti.C, George.G, Vishanth.W "Evaluating Global e-Government Sites: A View using Web Diagnostic Tools," Academic Conferences and publishing International October 2004

2. Naci K, Marijn J, "Evaluating websites from a public value perspective: A review of Turkish local government websites" International Journal of Information Management, vol.34, pp.315-363, 2014.

3. Gregory A, "Linking public sector social media and e-government website use to trust in government" Government Information Quarterly,vol33,pp.291304, 2016

4. Y.Z.Sha, X.Ouyang, "Evaluation of the influence of Chinese provincial government websites-website link analysis and network influence factor measurement," Information and Documentation Services, vol.06, pp.17-22. 2004.

5. J.L.Yang, Q.L.Liu, and X.Wu, "Research on the Evaluation of E-government Construction Effectiveness of Chinese Provincial Government Websites-Based on the Comparison of Website Link Analysis and Content Analysis," Library \& Information Studies, vol.04, pp.37-40, 2019.

6. K.Arif and I. Haroon, "Article information:calculating web impact factor for university websites of pakistan," Electron. Libr. vol. 33, no. 5, pp. 883-895, 2015.

7. Ingwersen.P, The calculation of Web Impact Factors. Jounal of documentation, vol54, pp.236-243, 1998.

8. A. B. A. Bakar and N. P. N. Leyni, "Webometric study of world class universities websites. Qualitative and quantitative methods in libraries (qqml)," Special Issue Bibliometrics and Scientometrics, pp. 105-115, 2015.

9. W.H.Lu, J.Y.Ye, "Analysis of the application status of link analysis method in domestic website empirical research," Library and Information Service, vol.18, pp.119-130. 2019.

10. J.L.Deng,"The Theory and Method of Social Economic Gray System," Social Sciences in China,vol.06,pp.47-60, 1984. 